\title{
Familial occurrence of nodular regenerative hyperplasia of the liver: a report on three families
}

\author{
J Dumortier, O Boillot, M Chevallier, F Berger, P Potier, P-J Valette, P Paliard, J-Y Scoazec
}

Fédération des

Spécialités Digestives,

Hôpital Edouard

Herriot, Lyon, France

J Dumortier

O Boillot

P-J Valette

P Paliard

INSERM U45, Hôpital

Edouard Herriot,

Lyon, France

J Dumortier

J-Y Scoazec

Laboratoire

d'Anatomie

Pathologique,

Fondation Mérieux,

Lyon, France

M Chevallier

Laboratoire Central

d'Anatomie et

Cytologie

Pathologiques, Hôpital

Edouard Herriot,

Lyon, France

F Berger

J-Y Scoazec

Service

d'Hépato-Gastro-

Entérologie, Centre

Hospitalier Lyon Sud,

Pierre Bénite, France

P Potier

Correspondence to:

Dr J Dumortier, INSERM

Unité 45, pavillon Hbis,

Hôpital Edouard Herriot

69437 Lyon Cedex 03,

France.

Accepted for publication

17 February 1999

\begin{abstract}
BackgroundlAims-Nodular regenerative hyperplasia of the liver is a histological lesion usually associated with systemic diseases, haematological malignancies, or drugs. Its prognosis depends on portal hypertension, which usually is well tolerated and requires medical management only.

Patients-Three unrelated families, in which two sibling adult male patients presented with nodular regenerative hyperplasia of the liver, were studied.

Methods-Complete clinical charts and liver biopsy specimens were available for all patients. In addition, explanted livers were available for examination for the two transplanted patients.

Results-There was no evidence of any of the various clinical situations known to be associated with nodular regenerative hyperplasia of the liver. Portal hypertension was severe, requiring surgical treatment in two cases. Renal lesions were present in three patients. In two patients, progressive evolution to liver atrophy and hepatic failure, associated with renal failure, led to combined liver and renal transplantation. Conclusions-This report describes the existence of familial cases of nodular regenerative hyperplasia of the liver, occurring without underlying or associated systemic disease, characterised by a poor clinical course and often associated with progressive renal failure.

(Gut 1999;45:289-294)
\end{abstract}

Keywords: nodular regenerative hyperplasia; liver; transplantation; familial

Nodular regenerative hyperplasia of the liver (NRHL) is defined by the occurrence of nodules of regenerative hepatocytes, diffusely distributed all over the hepatic parenchyma, in the absence of fibrosis. ${ }^{1-3}$ The clinical expression of this histological lesion is variable. The prognosis depends on the existence and severity of portal hypertension, which occurs in about $50 \%$ of cases, either as a presenting symptom or as a late complication. ${ }^{4}$ In most instances, NRHL is diagnosed in association with systemic diseases, such as connective tissue diseases, autoimmune disorders, or haematological malignancies. ${ }^{4-10}$ Some cases of NRHL have been attributed to toxic liver injury, after treatment with azathioprine or as part of the toxic oil syndrome. ${ }^{911-15}$ In most of these situations, no definite relation between the liver regenerative lesions and the associated clinical context has been established. However, it is usually assumed that the development of NRHL is secondary to microcirculatory disturbances, related either to lesions of small intrahepatic venous or arterial vessels, or to primary alterations of the sinusoidal wall. ${ }^{16}$

We here report the occurrence of liver lesions typical of NRHL in several members of three unrelated families. Besides their highly unusual familial occurrence, these cases of NRHL are also characterised by: (a) the absence of associated systemic disease or exposure to potentially toxic agents; $(b)$ poor clinical progress, related to severe portal hypertension, leading to orthotopic liver transplantation in two patients; and (c) the existence of vascular alterations involving other organs, such as the kidney.

\section{Materials and methods}

The present report is based on six patients, belonging to three unrelated families, for whom the diagnosis of NRHL was made between 1987 and 1993.

For all patients, complete clinical charts were available. Liver biopsy specimens were obtained from all patients. In addition, explanted livers were available for examination for the two transplanted patients. Sections from formalin fixed paraffin embedded liver tissue were stained with haematoxylin and fuchsin, chromotrope, Perls' iron stain, and Masson's reticulin.

\section{Results}

CASE REPORTS

Table 1 gives the salient clinical findings for each patient, and table 2 gives the liver function tests and results of computed tomography and endoscopic examination. No patient presented with a history of alcohol abuse, chronic hepatic disease, or blood transfusions. There was no sign of autoimmune or connective tissue disease. The patients were not taking any drugs at time of admission. Hepatitis B surface antigen and anti-HBs and anti-HBc antibodies were absent. Hepatitis C virus serology was negative. Anti-nuclear, anti-mitochondrial, anti-smooth muscle, and anti-endoplasmic reticulum antibodies were not detectable. Serum concentrations of ferritin, copper, caeruloplasmin, $\alpha_{1}$ antitrypsin, and $\alpha$ fetoprotein were within the normal limits. Serum protein electrophoresis and immunoelectrophoresis were normal. Rheumatoid factor was not detectable. For all patients, there was no abnormality in the coagulation cascade.

Abbreviation used in this paper: NRHL, nodular regenerative hyperplasia of the liver. 
Table 1 Clinical findings in the patients of the study group

\begin{tabular}{|c|c|c|c|c|c|c|}
\hline Case & $\operatorname{Age} e^{\star}$ & Sex & Associated manifestations & Circumstances of the diagnosis & Treatment & Complications \\
\hline 1 & 40 & M & - & Upper gastrointestinal bleeding & $\begin{array}{l}\text { Sclerotherapy, } \\
\text { mesenterico-caval shunt }\end{array}$ & $\begin{array}{l}\text { Portal hypertension, } \\
\text { encephalopathy }\end{array}$ \\
\hline 2 & 59 & M & Renal failure & Asymptomatic oesophageal varices & $\begin{array}{l}\text { Propranolol, } \\
\text { sclerotherapy, } \\
\text { liver transplantation }\end{array}$ & $\begin{array}{l}\text { Portal hypertension, } \\
\text { ascites, } \\
\text { encephalopathy }\end{array}$ \\
\hline 3 & 40 & $M$ & $\begin{array}{l}\text { Renal failure } \\
\text { Raynaud's phenomenon }\end{array}$ & $\begin{array}{l}\text { Asymptomatic cholestasis and elevated } \\
\text { aminotransferase levels }\end{array}$ & $\begin{array}{l}\text { Propranolol, } \\
\text { liver transplantation }\end{array}$ & Portal hypertension \\
\hline 4 & 38 & M & Renal failure & Elevated aminotransferase levels & - & - \\
\hline 5 & 28 & M & - & Leucothrombocytopenia & Propranolol & Portal hypertension \\
\hline 6 & 33 & M & - & Upper gastrointestinal bleeding & $\begin{array}{l}\text { Sclerotherapy, } \\
\text { propranolol }\end{array}$ & Portal hypertension \\
\hline
\end{tabular}

^At time of the diagnosis.

Table 2 Laboratory data and imaging findings in the patients of the study group

\begin{tabular}{|c|c|c|c|c|c|c|}
\hline & Case 1 & Case 2 & Case 3 & Case 4 & Case 5 & Case 6 \\
\hline Laboratory findings & (Dg/pres) & $(\mathrm{Dg} / \mathrm{OLT})$ & $(\mathrm{Dg} / \mathrm{OLT})$ & (Dg/pres) & (Dg/pres) & (Dg/pres) \\
\hline Serum albumin $(\mathrm{g} / \mathrm{l})$ & $39 / 37$ & $36 / 30$ & $38 / 37$ & $45 / 44$ & $44 / 40$ & $42 / 41$ \\
\hline Prothrombin (\% of normal) & $88 / 64$ & $89 / 66$ & $100 / 80$ & $100 / 100$ & $64 / 72$ & $78 / 75$ \\
\hline Serum bilirubin $(\mathrm{mmol} / \mathrm{l})$ & $18 / 10$ & $28 / 26$ & $15 / 21$ & $16 / 14$ & $20 / 49$ & $22 / 24$ \\
\hline Serum creatinine $(\mu \mathrm{mol} / \mathrm{l})$ & $79 / 83$ & $89 / 168$ & $78 / 177$ & $85 / 220$ & $78 / 77$ & $68 / 72$ \\
\hline Creatinine clearance $(\mathrm{ml} / \mathrm{min})$ & NA/NA & $\mathrm{NA} / 59$ & $\mathrm{NA} / 50$ & $\mathrm{NA} / 40$ & NA/NA & NA/NA \\
\hline Proteinuria & $\mathrm{NA} / \mathrm{NA}$ & $\mathrm{NA} /+$ & $+/+$ & $\mathrm{NA} /+$ & $-/-$ & $\mathrm{NA} / \mathrm{NA}$ \\
\hline Haematuria & NA/NA & $\mathrm{NA} /+$ & $+/+$ & $\mathrm{NA} /+$ & $-1-$ & NA/NA \\
\hline$\gamma$-Glutamyl transferase (IU/l) & $\mathrm{N} / \mathrm{N}$ & $1.5 \mathrm{~N} / \mathrm{N}$ & $4 \mathrm{~N} / \mathrm{N}$ & $\mathrm{N} / 1.5 \mathrm{~N}$ & $3 \mathrm{~N} / 4 \mathrm{~N}$ & $3 \mathrm{~N} / 5 \mathrm{~N}$ \\
\hline Alkaline phosphatase (IU/l) & $\mathrm{N} / \mathrm{N}$ & $1.5 \mathrm{~N} / \mathrm{N}$ & $2 \mathrm{~N} / \mathrm{N}$ & $\mathrm{N} / 2 \mathrm{~N}$ & $1.5 \mathrm{~N} / 1.5 \mathrm{~N}$ & $1.5 \mathrm{~N} / \mathrm{N}$ \\
\hline Aspartate aminotransferase (IU/l) & $\mathrm{N} / \mathrm{N}$ & $\mathrm{N} / 2 \mathrm{~N}$ & $1.5 \mathrm{~N} / \mathrm{N}$ & $1.5 \mathrm{~N} / \mathrm{N}$ & $1.5 \mathrm{~N} / 1.5 \mathrm{~N}$ & $1.5 \mathrm{~N} / 1.5 \mathrm{~N}$ \\
\hline Alanine aminotransferase (IU/1) & $\mathrm{N} / \mathrm{N}$ & $\mathrm{N} / \mathrm{N}$ & $1.5 \mathrm{~N} / \mathrm{N}$ & $2 \mathrm{~N} / \mathrm{N}$ & $1.5 \mathrm{~N} / \mathrm{N}$ & $1.5 \mathrm{~N} / 1.5 \mathrm{~N}$ \\
\hline \multicolumn{7}{|l|}{$\mathrm{CT}$ and endoscopic findings } \\
\hline Liver appearance & $\begin{array}{l}\text { Hepatomegaly/ } \\
\text { hepatomegaly }\end{array}$ & $\begin{array}{l}\text { Atrophy/ } \\
\text { atrophy }\end{array}$ & $\begin{array}{l}\text { Normal/ } \\
\text { atrophy }\end{array}$ & $\begin{array}{l}\text { Hepatomegaly/ } \\
\text { hepatomegaly }\end{array}$ & $\begin{array}{l}\text { Hepatomegaly/ } \\
\text { atrophy }\end{array}$ & $\begin{array}{l}\text { Hepatomegaly/ } \\
\text { hepatomegaly }\end{array}$ \\
\hline Portosystemic communications & Yes/no & Yes/yes & No/yes & No/no & Yes/yes & Yes/yes \\
\hline Splenomegaly & Yes/(splenectomy) & No/yes & No/yes & $\mathrm{No} /$ no & Yes/yes & Yes/yes \\
\hline Oesophageal varices & Yes/no ${ }^{\star}$ & Yes $/ \mathrm{no}^{\star}$ & No/yes & $\mathrm{No} / \mathrm{no}$ & Yes/yes & Yes/yes \\
\hline
\end{tabular}

NA, not available; Dg, at time of the diagnosis; OLT, when referred for orthotopic liver transplant; pres, at the present time; $\mathrm{xN}$, $\mathrm{x}$ upper normal value; CT, computed tomography.

*After sclerotherapy.

We summarise below the clinical histories of each patient.

Family 1

In this family, two brothers presented with NRHL.

Patient 1-The patient was admitted to our hospital in October 1987, at the age of 40 years, for haematemesis. Upper gastrointestinal endoscopy confirmed the source of bleeding as oesophageal varices. The bleeding was not controlled by conservative measures and oesophageal transection was performed. On physical examination, there was a hepatomegaly and a splenomegaly. Abdominal ultrasonography confirmed the existence of hepatosplenomegaly and showed an enlarged splenic vein. Portal and hepatic vein patency was assessed by ultrasonographic pulsed Doppler. A transjugular hepatic biopsy specimen was taken for histological examination. Two other percutaneous hepatic biopsies were performed in 1987 and 1988. Between 1988 and 1989, injection sclerotherapy was needed to achieve complete eradication of oesophageal varices.

The patient was admitted again in September 1990 for a recurrence of oesophageal variceal bleeding. A decision to treat surgically was taken. A lateral mesenterico-caval shunt was performed. At surgery, a portal vein thrombosis was discovered and confirmed by peroperative ultrasonography. Macroscopically, the liver was atrophic and presented a markedly irregular surface. Because of a thrombotic obstruction of the first shunt, a new shunt was inserted in March 1991.

From 1991 to 1997, there was no further gastrointestinal bleeding. In 1997, at the age of 57, the patient presented with an episode of hepatic encephalopathy. A full blood count showed pancytopenia. The prothrombin index was $64 \%$. There was no recurrence of oesophageal varices. Abdominal ultrasonography showed no ascites and no sign of portal hypertension. A third hepatic biopsy was performed. At the date of submission of the manuscript, the patient is alive with recurrent episodes of hepatic encephalopathy.

Patient 2-This 59 year old white man was referred to our department in December 1992 because of the incidental endoscopic diagnosis of oesophageal varices. A treatment combining propranolol adminstration and injection sclerotherapy was begun. A percutaneous hepatic biopsy specimen was taken for histological examination. In 1995, at the age of 62 , the patient progressively developed ascites and hepatic encephalopathy. Physical examination disclosed splenomegaly. There was no jaundice. A full blood count showed pancytopenia. The prothrombin index was $66 \%$. Abdominal ultrasonography with pulsed Doppler confirmed the existence of ascites and splenomegaly and showed an atrophic liver. There was evidence of large collateral venous channels within the abdomen. The coeliac and superior mesenteric angiograms showed a tortuous splenic vein with retrograde flow down the superior mesenteric vein communicating 
with the inferior vena cava. Portal and hepatic veins were patent. Upper gastrointestinal endoscopy confirmed eradication of oesophageal varices.

In addition to symptoms related to hepatocellular insufficiency and portal hypertension, the patient also showed signs of altered renal function. Serum creatinine levels were increased to $168 \mathrm{mmol} / 1$ (normal range 55-120). Creatinine clearance was $59 \mathrm{ml} / \mathrm{min}$. Haematuria and proteinuria were present. Examination of a renal biopsy specimen showed severe nephroangiosclerosis of vascular origin.

Further clinical progress was poor, with recurrent episodes of tense ascites and encephalopathy and progressive degradation of renal function leading to renal insufficiency. A decision to carry out combined liver and renal transplantation was taken in December 1995. The combined transplantation was performed in January 1996. The recovery was uneventful. At the date of submission of the manuscript, the patient is alive, without symptoms of hepatic or renal disease.

Family 2

Two brothers of this family presented with NRHL. Both were HLA A1B7. Their mother died at the age of 56 from hepatic failure of unknown cause.

Patient 3-This 40 year old white man was referred in October 1987 for diagnostic evaluation after the incidental discovery of abnormal liver tests. A first surgical hepatic biopsy specimen was taken for histological examination, during treatment of an inguinal hernia. Upper gastrointestinal endoscopy showed oesophageal varices, which were treated by injection sclerotherapy. A percutaneous hepatic biopsy specimen was taken for histological examination. In addition to abnormal liver tests and signs of portal hypertension, the patient also exhibited haematuria and proteinuria.

From 1988 to 1996, regular follow up showed the persistence of abnormal liver tests and a progressive alteration of renal function. No further clinical complications occurred. In March 1996, upper gastrointestinal endoscopy and abdominal ultrasonography showed aggravation of portal hypertension. A decision to treat surgically was taken and a lateral mesenterico-caval shunt was performed in September 1996. At this time, a second surgical hepatic biopsy specimen was taken for histological examination. Further clinical progress was poor. The patient had chronic oedema and suffered several episodes of hepatic encephalopathy. Renal insufficiency developed. A renal needle biopsy specimen showed non-specific lesions of nephroangiosclerosis. A decision to carry out combined liver and kidney transplantation was taken in March 1997. The transplantation was performed in December 1997. At surgery, the mesenterico-caval shunt was found to be permeable, without any evidence of thrombosis. After transplantation, the recovery was uneventful. At the date of submission of the manuscript, the patient is alive without evidence of hepatic or renal disease.
Patient 4-This 38 year old white man was seen in April 1990 for diagnostic evaluation of an isolated increase in serum aminotransferase levels. Upper gastrointestinal endoscopy showed no evidence of oesophageal varices. Abdominal ultrasonography showed hepatomegaly. A percutaneous liver biopsy was performed. Regular follow up between 1990 and 1996 diagnosed no further clinical or biological abnormalities.

In September 1996, renal tests were found to be abnormal. Serum creatinine level was increased to $135 \mathrm{mmol} / 1$ (normal range 55120). Haematuria and proteinuria were present. In September 1997, the serum creatinine level was further increased to $220 \mathrm{mmol} / \mathrm{l}$, and creatinine clearance was $45 \mathrm{ml} / \mathrm{min}$. A renal needle biopsy specimen was obtained and showed nephroangiosclerosis. At the date of submission of the manuscript, the patient is alive.

\section{Family 3}

In this family, two brothers presented with NRHL.

Patient 5-The patient was first admitted in July 1992, at the age of 28, for leucothrombocytopenia. Upper gastrointestinal endoscopy showed oesophageal varices. Physical examination disclosed hepatomegaly and splenomegaly. Abdominal ultrasonography confirmed the existence of hepatosplenomegaly and showed an enlarged splenic vein. Portal and hepatic vein patency was documented by ultrasonographic pulsed Doppler. A percutaneous hepatic biopsy specimen was taken for histological examination. Propranolol, $160 \mathrm{mg}$ a day, was begun.

From 1992 to 1998, there was no gastrointestinal bleeding. Thrombosis of the left portal vein was diagnosed in February 1998.

Patient 6-This 33 year old white man was referred in October 1993 for haematemesis. Upper gastrointestinal endoscopy confirmed the source of bleeding as oesophageal varices. The bleeding was controlled by conservative measures. On physical examination, there was a hepatomegaly and a splenomegaly, confirmed by abdominal ultrasonography. Portal and hepatic vein patency was documented by ultrasonographic pulsed Doppler. A percutaneous hepatic biopsy specimen was taken for histological examination. Between 1993 and 1994, injection sclerotherapy was needed to achieve complete eradication of oesophageal varices. Propranolol, $160 \mathrm{mg}$ a day, was begun.

The patient was admitted again in October 1996 for a recurrence of oesophageal variceal bleeding.

From 1996 to 1998, there was no further gastrointestinal bleeding despite the persistence of oesophageal varices.

\section{PATHOLOGICAL FINDINGS}

In all cases, examination of liver biopsy specimens showed diagnostic features of nodular regenerative hyperplasia. The overall architecture of the liver was distorted by the presence of small nodules of hepatocytes 


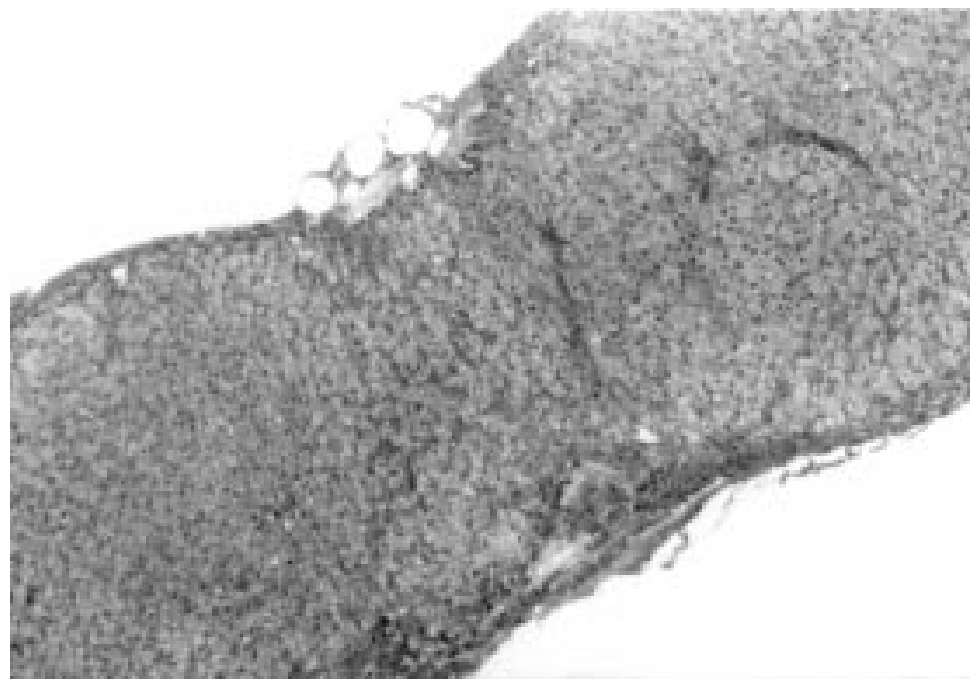

Figure 1 Low power magnification of a liver biopsy sample from patient 2. Two distinct regenerative nodules, separated by compressed hepatocytic plates, are well visible. Haematoxylin-fuchsin stain; original magnification $\times 120$.

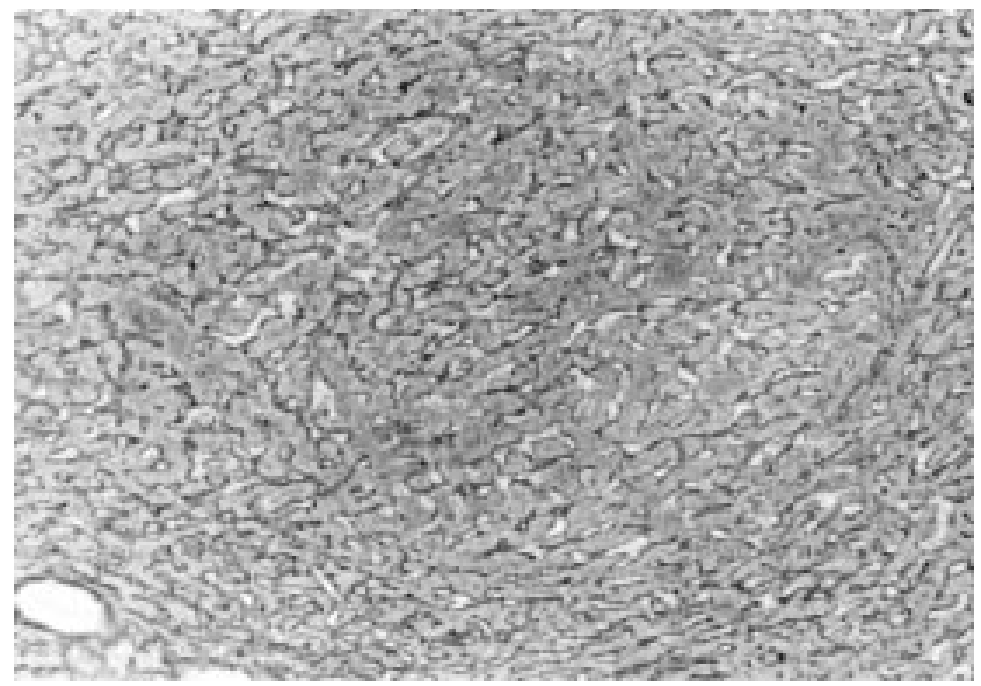

Figure 2 On the liver explant from patient 2, the typical pattern of nodular regenerative hyperplasia of the liver is well visualised by the reticulin stain. A regenerative nodule is surrounded by atrophic and disorganised hepatocytic plates. Masson's reticulin stain; original magnification $\times 80$.

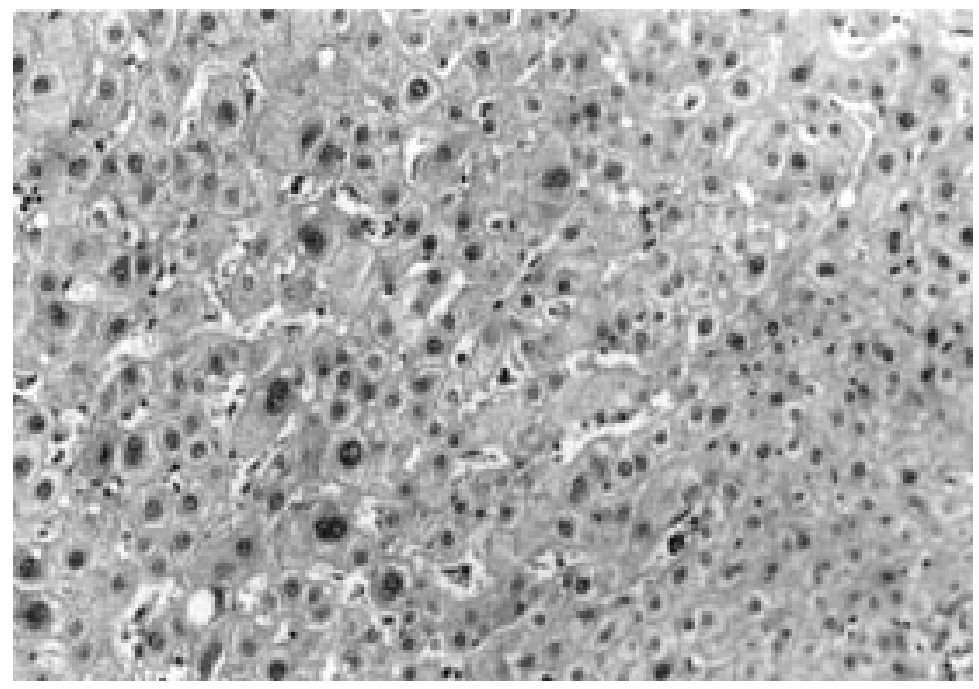

Figure 3 In patient 3, foci of hepatocytes with pseudo-dysplastic features are present. Haematoxylin-fuchsin stain; original magnification $\times 250$. directly merging into the adajcent liver parenchyma (fig 1).

Within hepatic nodules, hepatocytes were usually swollen and enlarged. They were organised into plates of irregular thickness, separated by well differentiated sinusoid vessels. The periphery of the nodules was outlined by compressed and sometimes atrophic hepatocytic plates, best visualised by using reticulin stains (fig 2). No fibrous capsule was detectable. The nodules were separated by dilated sinusoid vessels. On biopsy specimens, no occlusive vascular lesion was observed. No abnormality in portal vessels and centrolobular veins was detected.

When successive biopsy specimens were available from the same patient (cases 2 and 3), no significant modification of the histological appearance was observed.

In the two transplanted patients (cases 1 and 3), explanted livers were available for examination. In patient 1 , the liver $(1040 \mathrm{~g})$ was atrophic and markedly cholestatic. Cut sections had a distinctive nodular appearance. At histological examination, the diagnosis of NRHL was confirmed. The overall parenchyma was distorted by small hepatocytic nodules, separated by compressed and atrophic liver plates. Within regenerative nodules, the presence of large hepatocytes with voluminous and nucleolated nuclei was noted. Additional features included severe cholestasis with numerous intracanalicular biliary thrombi and slight haemosiderosis. Despite careful examination, no vascular occlusion was detected. No abnormality of portal vessels or centrilobular veins was observed.

The explanted liver of patient 3 weighed 1520 g. Cut sections had a distinctive nodular appearance. Large haemorrhagic foci were disseminated within the parenchyma. At histological examination, the diagnosis of NRHL was confirmed. Small regenerative hepatocytic nodules were diffusely distributed within the overall parenchyma. Mild cholestasis was common. In some nodules, hepatocytes were considerably enlarged and had large irregular heavily nucleolated nuclei, reminiscent of those observed in large cell dysplasia (fig 3). In the peripheral regions of the liver, additional architectural abnormalities were observed. A proportion of portal tracts was enlarged by non-inflammatory periportal fibrosis, associated with mild neoductular proliferation. In some instances, bridging fibrosis between adjacent portal tracts could be observed (fig 4). In the subcapsular region, bridging fibrosis resulted in the formation of thick fibrous bands separating small regenerative nodules. Careful examination of large hepatic vessels showed the existence of two organised thrombotic occlusions, located within large intrahepatic branches of the portal vein. In addition, numerous dilated venous and lymphatic vessels, sometimes lined by a thickened and fibrotic wall, were present in the large perihilar portal tracts. 


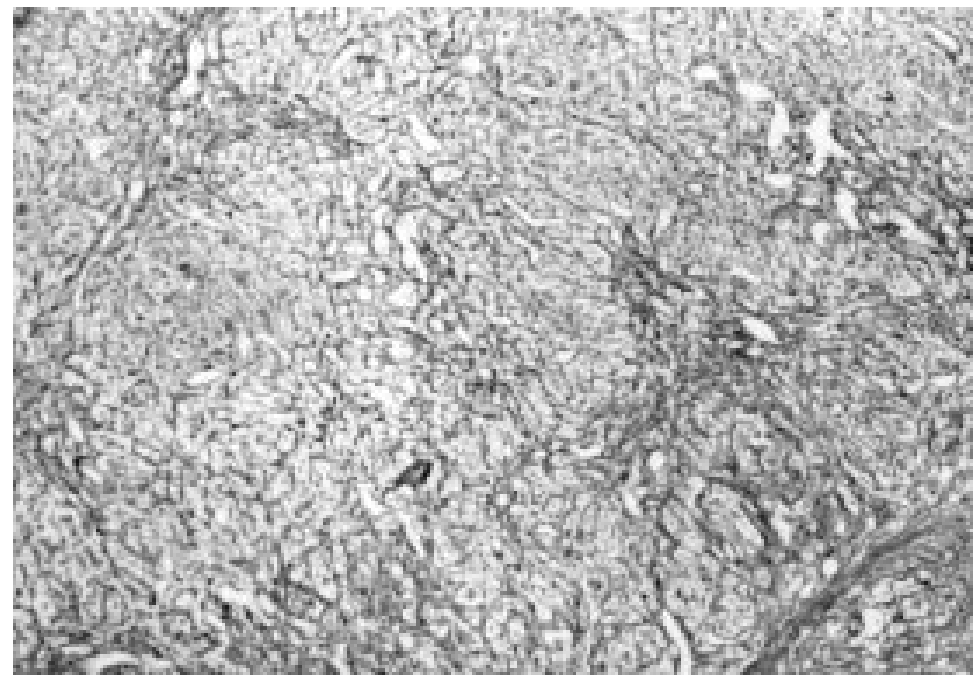

Figure 4 Low power magnification of the subcapsular area of the liver explant obtained from patient 3. The overall architecture is distorted by extensive fibrotic septa. Masson's reticulin stain; original magnification $\times 60$.

\section{Discussion}

We report the occurrence in three unrelated families of a syndrome associating nodular regenerative hyperplasia of the liver and severe portal hypertension. Clinical progress was usually poor and justified combined liver and renal transplantation in two patients.

To the best of our knowledge, the familial occurrence of NRHL has not been reported so far. However, three previous reports have documented familial cases of hepatoportal sclerosis ${ }^{17} 18$ and incomplete septal cirrhosis, ${ }^{19}$ which are usually considered to be closely related to NRHL and may be part of the same spectrum of liver lesions.

In our cases, the initial diagnosis of NRHL was made on liver biopsy specimens and, in two cases, were later confirmed by examination of explanted livers after orthotopic transplantation. The histological picture was usually typical, characterised by diffuse involvement of the liver parenchyma by small nodules composed of regenerative hepatocytes, with no or minimal fibrosis. In one patient, examination of the explanted liver after orthotopic liver transplantation confirmed the diffuse distribution of the lesions and their homogeneous appaearance. In another patient, the explanted liver showed a more heterogeneous picture reminiscent of that of incomplete septal cirrhosis. ${ }^{20-22}$ Our observation further illustrates the close relations that probably exist between NRHL and incomplete septal cirrhosis. ${ }^{22} 23$

Interestingly, cytological features like those observed in large cell dysplasia were observed in two of our patients. The occurrence of such dysplastic features has been previously reported in other cases of NRHL or related histological lesions, such as incomplete septal cirrhosis. ${ }^{24}$ In certain series of NRHL, the incidence of dysplasia amounted to $40 \%$ of cases. ${ }^{9}$ Its exact significance is unknown but it is likely to be related to the increased proliferative activity of hepatocytes constituting the regenerative nodules.
Portal hypertension and its complications dominated the clinical course of our patients. While portal hypertension is a usual consequence of NRHL, its development is far from constant. An incidental finding of NRHL is possible in patients without clinical evidence of liver disease. ${ }^{422526}$ Moreover, the development of portal hypertension was particularly severe in our patients. It was the presenting symptom in two of them, resulting in repeated episodes of bleeding from oesophageal varices in one, and requiring surgical treatment in two, respectively three and nine years after the initial diagnosis. In addition, in two of our patients, symptoms of rapidly progressing liver failure led to the decision for a liver transplantation after respectively four and 10 years of follow up. The severity of the clinical course experienced by several of our patients is highly unusual in NRHL, which, in most cases, is well tolerated and requires medical treatment only. ${ }^{4}$ So far, liver transplantation has been reported in only four patients with histologically proven NRHL. ${ }^{24}$ 27-29 In these cases, as in our patients, recovery was uneventful and no recurrence of the disease observed. We avoided azathioprine administration, as this immunosuppressive drug has been incriminated in the pathogenesis of NRHL occurring after kidney transplantation. ${ }^{30}$

Our patients showed no evidence of the various underlying diseases known to be associated with NRHL. ${ }^{4-10}$ There were no symptoms suggestive of systemic disease or haematological malignancies. There was no evidence of exposure to toxic agents that could potentially be responsible for the development of NRHL, such as azathioprine. So far, the apparent de novo occurrence of NRHL, without underlying or associated disease, has been the exception and only a few cases have been reported in the literature. ${ }^{31}$

The causes of NRHL in our patients remain to be established. The familial occurrence of our cases raises the possibility of a congenital disorder. The existence of NRHL in children is rare, but possible, and some of the cases reported in the literature have been found in association with various congenital disorders. ${ }^{32}$ In our cases, an early onset of the disease with a late diagnosis favoured by the existence of symptoms related to portal hypertension is possible. This is suggested by the morphological appearance of the liver lesions. The existence of liver atrophy in three cases and the association with lesions of incomplete septal cirrhosis in another are in keeping with a late stage of evolution. However, unidentified environmental factors cannot be definitely excluded. For instance, experimental reports have shown that NRHL-like lesions may be observed after lead poisoning ${ }^{33}$ or selenium exposure. $^{34}$

NHRL is currently thought to be secondary to microcirculatory disturbances within the liver parenchyma, inducing successive episodes of atrophy followed by compensatory regeneration. ${ }^{16}$ Several lines of evidence suggest that vascular lesions may actually be involved in the pathogenesis of the lesions observed in our patients. As in several previous 
cases of NRHL, ${ }^{4}{ }^{9}$ thrombotic occlusions of the portal vein or its large branches were found in three of our patients. It is not possible to exclude the existence of liver vascular lesions in the other patients, as the focal nature of their distribution may result in their misdiagnosis. In addition, several of our patients presented with lesions of vascular origin involving other organs. One patient had myocardiopathy and Raynaud's phenomenon. Three others had progressive renal failure, related to nephroangiosclerosis of vascular origin. In two of these patients, renal transplantation was required. The association between NRHL and renal failure has been previously noted, ${ }^{35}{ }^{36}$ and reinforces the concept that some cases of NRHL may be part of a multiorgan involvement of the microcirculation.

In conclusion, this report points out the existence of familial cases of NRHL, occurring without underlying or associated systemic disease, characterised by a poor clinical course leading to severe portal hypertension and progressive hepatocellular insufficiency requiring liver transplantation, and often associated with progressive renal failure requiring kidney transplantation.

We are grateful to Mrs M F Jacquier (INSERM U45, Lyon France) for her help with preparation of the figures and to Dr T Bizollon (Hotel-Dieu, Lyon, France) for helpful discussions about NRHL.

1 Steiner PE. Nodular regenerative hyperplasia of the liver. Am f Pathol 1959;35:943-53.

2 Ranstrom S. Miliary hepatocellular adenomatosis. Acto Pathol Microbiol Scand 1953;33:225-9.

3 Stromeyer FW, Ishak KG. Nodular transformation (nodular "regenerative" hyperplasia) of the liver. A clinicopathologic study of 30 cases. Hum Pathol 1981;12:60-71.

4 Wanless IR. Micronodular transformation (nodular regenerative hyperplasia) of the liver: a report of 64 cases among 2,500 autopsies and a new classification of benign hepato2,500 autopsies and a new classification of be

5 Blendis LM, Parkinson MC, Shilkin KB, et al. Nodular Blendis LM, Parkinson MC, Shilkin KB, et al. Nodular
regenerative hyperplasia of the liver in Felty's syndrome. $Q$ regenerative hyperplasia

6 Harris M, Rash RM, Dymock IW. Nodular, non-cirrhotic Harris M, Rash RM, Dymock IW. Nodular, non-cirrhotic
liver associated with portal hypertension in a patient with liver associated with portal hypertension in a patien
rheumatoid arthritis. 7 Clin Pathol 1974;27:963-6.

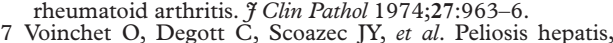
nodular regenerative hyperplasia of the liver, and lightchain deposition in a patient with Waldenstrom's macroglobulinemia. Gastroenterology 1988;95:482-6.

8 McMahon RF, Babbs C, Warnes TW. Nodular regenerative hyperplasia of the liver, CREST syndrome and primary biliary cirrhosis: an overlap syndrome? Gut 1989;30:14309 Colina

9 Colina F, Alberti N, Solis JA, et al. Diffuse nodular regenerative hyperplasia of the liver (DNRH). A clinicopathologic study of 24 cases. Liver 1989;9:253-65.

10 Cadranel JF, Cadranel J, Buffet C, et al. Nodular regenerative hyperplasia of the liver, peliosis hepatis, and perisinutive hyperplasia of the liver, peliosis hepatis, and perisinuphadenopathy and severe hypoxemia. Gastroenterology phadenopathy and

11 Buffet C, Cantarovitch M, Pelletier G, et al. Three cases of nodular regenerative hyperplasia of the liver following renal transplantation. Nephrol Dial Transplant 1988;3:327-30.

12 Bredfeldt JE, Havey AL. Nodular regenerative hyperplasia of the liver following renal transplantation. Dig Dis Sci 1981;26:271-4
13 Gane E, Portmann B, Saxena R, et al. Nodular regenerative hyperplasia of the liver graft after liver transplantation. Hepatology 1994;20:88-94.

14 Mion F, Napoleon B, Berger F, et al. Azathioprine induced liver disease: nodular regenerative hyperplasia of the liver and perivenous fibrosis in a patient treated for multiple sclerosis. Gut 1991;32:715-17.

15 Solis-Herruzo JA, Vidal JV, Colina F, et al. Nodular regenerative hyperplasia of the liver associated with the toxic oil syndrome: report of five cases. Hepatology 1986;6: 687-93

16 Wanless IR, Godwin TA, Allen F, et al. Nodular regenerative hyperplasia of the liver in hematologic disorders: a possible response to obliterative portal venopathy. A morphometric study of nine cases with an hypothesis on the pathogenesis. Medicine (Baltimore) 1980;59:367-79.

17 Maugard T, David A, Nomballais MF, et al. Hepatoportal sclerosis: apropos of a familial case. Arch Pediatr 1997;4: 251-4.

18 Sarin SK, Mehra NK, Agarwal A, et al. Familial aggregation in noncirrhotic portal fibrosis: a report of four families. $\mathrm{Am}$ 7 Gastroenterol 1987;82:1130-3.

19 Barnett JL, Appelman HD, Moseley RH. A familial form of incomplete septal cirrhosis. Gastroenterology 1992;102:6748.

20 Ludwig J, Hashimoto E, Obata $\mathrm{H}$, et al. Idiopathic portal hypertension; a histopathological study of 26 Japanese cases. Histopathology 1993;22:227-34.

21 Sciot R, Staessen D, Van Damme B, et al. Incomplete septal cirrhosis: histopathological aspects. Histopathology 1988;13: 593-603.

22 Nakanuma Y. Nodular regenerative hyperplasia of the liver: retrospective survey in autopsy series. $\mathcal{F}$ Clin Gastroenterol 1990;12:460-5.

23 Bernard PH, Le Bail B, Cransac M, et al. Progression from idiopathic portal hypertension to incomplete septal cirrhosis with liver failure requiring liver transplantation. $7 \mathrm{Hepa-}$ tol 1995;22:495-9.

24 Le Bail B, Bioulac-Sage P, Arnoux R, et al. Late recurrence of a hepatocellular carcinoma in a patient with incomplete Alagille syndrome. Gastroenterology 1990;99:1514-16.

25 Wanless IR, Bernier V, Seger M. Intrahepatic portal vein sclerosis in patients without a history of liver disease. An autopsy study. Am 7 Pathol 1982;106:63-70.

26 Haratake J, Horie A, Takasugi M, et al. Nodular regenerative hyperplasia of the liver associated with idiopathic membranous glomerulonephritis. Am f Gastroenterol 1987;82:67780

27 de Sousa JM, Portmann B, Williams R. Nodular regenerative hyperplasia of the liver and the Budd-Chiari syndrome. Case report, review of the literature and reappraisal of pathogenesis. F Hepatol 1991;12:28-35.

28 Elariny HA, Mizrahi SS, Hayes DH, et al. Nodular regenerative hyperplasia: a controversial indication for orthotopic liver transplantation. Transpl Int 1994;7:309-13.

29 McDonald JA, Painter DM, Gallagher ND, et al. Nodular regenerative hyperplasia mimicking cirrhosis of the liver. Gut 1990;31:725-7.

30 Nataf C, Feldmann G, Lebrec D, et al. Idiopathic portal hypertension (perisinusoidal fibrosis) after renal transplantation. Gut 1979;20:531-7.

31 Rougier P, Degott C, Rueff B, et al. Nodular regenerative hyperplasia of the liver. Report of six cases and review of the literature. Gastroenterology 1978;75:169-72.

32 Moran CA, Mullick FG, Ishak KG. Nodular regenerative hyperplasia of the liver in children. Am F Surg Pathol 1991; 15:449-54.

33 Hruban Z, Meehan T, Wollmann RL, et al. Diffuse nodular hyperplasia and fibrosis of the liver in lead-poisoned mandrills. F Med Primatol 1986;15:245-58.

34 Bioulac-Sage P, Dubuisson L, Bedin C, et al. Nodular regenerative hyperplasia in the rat induced by a seleniumenriched diet: study of a model. Hepatology 1992;16:41825.

35 Kaburaki J, Kuramochi S, Fujii T, et al. Nodular regenerative hyperplasia of the liver in a patient with systemic sclerosis. Clin Rheumatol 1996;15:613-16.

36 Haboubi NY, Smith VJ, Coyne JD, et al. Nodular regenerative hyperplasia of the liver in a non-treated patient with mesangiocapillary glomerulonephritis. Histopathology 1991;18:367-8. 